\title{
Effect of NaCl Doping on Growth, Characterization, Optical and Dielectric Properties of Potassium Hydrogen Phthalate (KHP) Crystals
}

\author{
R. K. Raju ${ }^{1}$, S. M. Dharamaprakash ${ }^{2}$, H. S. Jayanna ${ }^{{ }^{*}}$ \\ ${ }^{1}$ Department of Physics, Kuvempu University, Shankaraghatta, India \\ ${ }^{2}$ Department of Physics, Mangalore University, Mangalore, India \\ Email: ${ }^{*}$ jayanna60@gmail.com
}

Received 21 August 2015; accepted 27 September 2015; published 30 September 2015

Copyright (C) 2015 by authors and Scientific Research Publishing Inc.

This work is licensed under the Creative Commons Attribution International License (CC BY).

http://creativecommons.org/licenses/by/4.0/

\section{(c) (i) Open Access}

\begin{abstract}
Single crystals of sodium chloride doped Potassium Hydrogen Phthalate (KHP) were grown from aqueous solution by slow evaporation method at room temperature. The powder X-ray diffraction analysis was carried out and lattice cell parameters estimated. FTIR studies confirm the presence of functional groups and slight distortion of groups due to doping of sodium metal. UV-visible and photoluminescence spectral studies revealed to understand the optical properties. The NLO property of grown crystals has been confirmed by Kurtz powder technique. Dielectric studies of samples showed that dielectric constant decreased slowly with increasing frequency and attains saturation at higher frequencies.
\end{abstract}

Keywords

Crystal Growth, Second Harmonic Generation, Lattice Parameters, Dielectric Constant, Photoluminescence

\section{Introduction}

Second order nonlinear optical (NLO) materials have recently attracted much attention due to their potential applications in emerging optoelectronic technologies [1]. Materials with large optical nonlinearities with stable physical and thermal efficiencies required for many of these applications. Non-linear optical (NLO) materials

${ }^{*}$ Corresponding author.

How to cite this paper: Raju, R.K., Dharamaprakash, S.M. and Jayanna, H.S. (2015) Effect of NaCl Doping on Growth, Characterization, Optical and Dielectric Properties of Potassium Hydrogen Phthalate (KHP) Crystals. Advances in Materials Physics and Chemistry, 5, 399-407. http://dx.doi.org/10.4236/ampc.2015.510040 
have attracted and gained enormous demand due to their wide applications in the recent technologies like optoelectronics, optical communication and data storage systems [2] [3]. Potassium hydrogen phthalate (KHP) crystal, with chemical formula $\mathrm{K}\left(\mathrm{C}_{6} \mathrm{H}_{4} \mathrm{COOH} \cdot \mathrm{COO}\right)$, is well known material for its application in the production of crystal analyzers for long-wave X-ray spectrometers [4]-[7]. Phthalate single crystals are piezoelectrics with high coefficients of acousto-optical interaction [8] [9]. KHP crystallizes in orthorhombic structure with space group $P c a 2_{1}$ [10] [11]. It has platelet morphology with cleavage along (010) plane. This feature allows one to use them for data processing and intra laser modulation in various acousto optical devices [12]-[14]. It is important to search for new NLO material, which possesses large NLO coefficient, shorter cutoff wavelength, transparency in the UV region and higher laser damage threshold [15] [16]. Influence of alkali metal has strong effect on the material properties like morphology, optical and thermoluminescene [17] [18].

\section{Experimental}

\subsection{Crystal Growth}

Potassium Hydrogen Phthalate (KHP) analytical reagent (AR) grade was purified by repeated recrystallisation using double distilled water as solvent. The crystals were grown by slow evaporation solution growth technique (SEST) at room temperature. A saturated solution was prepared $(12 \mathrm{~g} / 100 \mathrm{ml}$ from literature) under slightly acidic conditions $\mathrm{pH}$ is 4.8 . Sodium Chloride (AR grade) of different concentration (1M\%, 3M\% and $5 \mathrm{M} \%$ ), were prepared and added $5 \mathrm{ml}$ each separately to the supersaturated solution of KHP. Pure and doped solution was stirred for 7 - $8 \mathrm{hr}$ using magnetic stirrer for homogeneous mixing. After homogeneous mixing solutions were transferred to clean Petri dish covered with polythene cover and perorations were made on polythene covers for proper evaporation of the solvent. The whole setup was kept in dust free area and closely monitored. Small crystals appeared in the beginning about 4 - 5 days for both pure and doped KHP, due to slow evaporation and grew larger in considerable time of about 15 - 20 days. At higher concentration of dopant, the adsorption film blocks the growth surface and inhibits the growth process [19].

Good quality optically transparent large size crystals were selected for carrying out the measurements. Photographs of grown doped and undoped crystals as shown in Figure 1.

\subsection{Characterisation}

In order to confirm the material of the crystal powder X-ray diffraction (PXRD) in the $2 \theta$ range $5^{\circ}$ to $70^{\circ}$ with $\mathrm{Cu} \mathrm{K}_{\alpha}(\lambda=1.5418 \AA$ ). The TG-DTA studies were carried out using TA-Instruments model NETZSCH TG 209 F1 with heat range $10^{\circ} \mathrm{C} / \mathrm{min}$. The FT-IR spectrum was recorded using Bruker-alpha for all crystals grown in the range of $400 \mathrm{~cm}^{-1}$ to $4000 \mathrm{~cm}^{-1}$. Ocean Optics UV-Vis-NIR spectrometer was used to study optical transparency

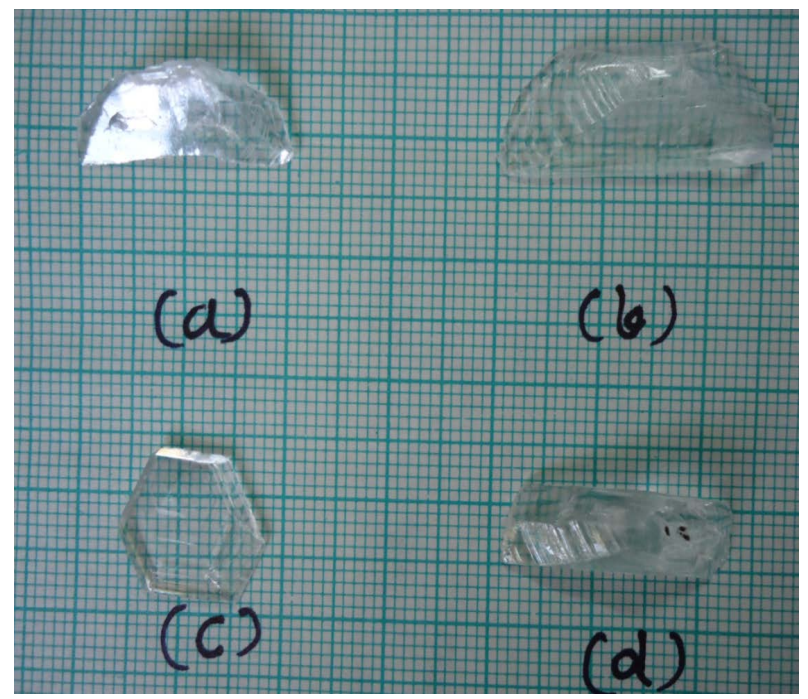

Figure 1. Photograph of grown crystals: (a) K0: Pure; (b) K1: 1M\%; (c) K2: 3M\% and (d) K3: 5M\% doped KHP. 
of the crystals between $200 \mathrm{~nm}$ to $900 \mathrm{~nm}$. The SGH test was carried by the Kurtz powder method. AN Nd:YAG laser with $1.064 \mu \mathrm{m}$ was made fall on samples packed in micro-capillary tube. SHG generated by randomly oriented microcrystals were detected by photomultiplier tube after filtration of incident radiation of $1.064 \mu \mathrm{m}$. The frequency doubling was confirmed by Green colour of the output radiation. The SHG were carried out for all grown crystals. The Photoluminescence studies were carried using Horiba Jobin YVON LabRam equipment. The dielectric study was carried out for pure and doped samples using impendence analysis Interface LCR meter model PSM 1735 N4L at room temperature.

\section{Results and Discussions}

\subsection{X-Ray Diffraction Analysis}

The pure and $\mathrm{NaCl}$ doped crystals were subjected to powder X-ray diffraction. Using the JCPDS with X'pert high Score plus software data were analyzed. It showed that doped KHP crystallizes in orthorhombic system with space group $P c a 2_{1}$. The calculated lattice parameters were in agreement with reported values [20]. The Ionic radius of $\mathrm{K}$ atom is slightly large compare to that of Na atom [21]. Hence it is reasonable to agree that the dopant can enter the crystalline matrix without much distortion. Very small minor changes in peak intensity due to lattice strains as result of doping but the basic crystalline structure remains the same. The obtained cell parameters are $\mathrm{a}=9.653 \AA, \mathrm{b}=13.461 \AA, \mathrm{c}=6.431 \AA \& \alpha=\beta=\gamma=90^{\circ}$ for pure KHP and $\mathrm{a}=9.577 \AA, \mathrm{b}=13.246$ $\AA, \mathrm{c}=6.463 \AA ; \mathrm{a}=9.628 \AA, \mathrm{b}=13.555 \AA, \mathrm{c}=6.518 \AA ; \mathrm{a}=9.844 \AA, \mathrm{b}=13.389 \AA, \mathrm{c}=6.340 \AA$ and $\alpha=\beta=\gamma=$ $90^{\circ}$ respectively for $1 \mathrm{M} \%$, 3M\% \& $5 \mathrm{M} \%$ of $\mathrm{NaCl}$ doped KHP crystals. The XRD spectra shown in Figure 2.

\subsection{FT-IR Spectral Studies}

The FT-IR spectral analysis was carried out in the region $4000-400 \mathrm{~cm}^{-1}$. The spectrum is shown in Figure 3 , the functional groups present were identified and a small shift is observed as result of $\mathrm{NaCl}$ doping. It is due to the lattice strain developed. In The spectra, that characteristic $\mathrm{OH}$ stretching peaks occur at $3441 \mathrm{~cm}^{-1}, 3443$ $\mathrm{cm}^{-1}, 3452 \mathrm{~cm}^{-1}$ for pure (0M\%) and doped (3M\% \& 5M\%) respectively shows shifting of vibrational absorptions. This could be due to lattice strain because of doping of $\mathrm{Na}^{+}$ion into crystal lattice [20]. The some of the stretching frequencies are given below (Table 1).

\subsection{Thermal Studies}

The TG-DTA curves of pure and doped crystals are shown in Figure 4. The analyses were carried out for pure

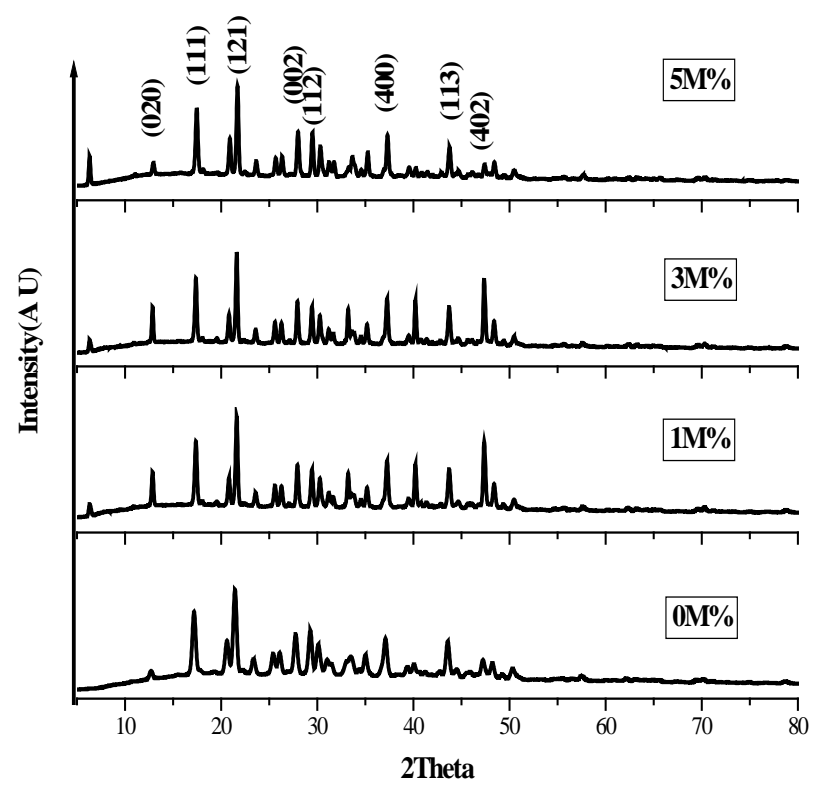

Figure 2. XRD pattern of pure and doped crystals. 


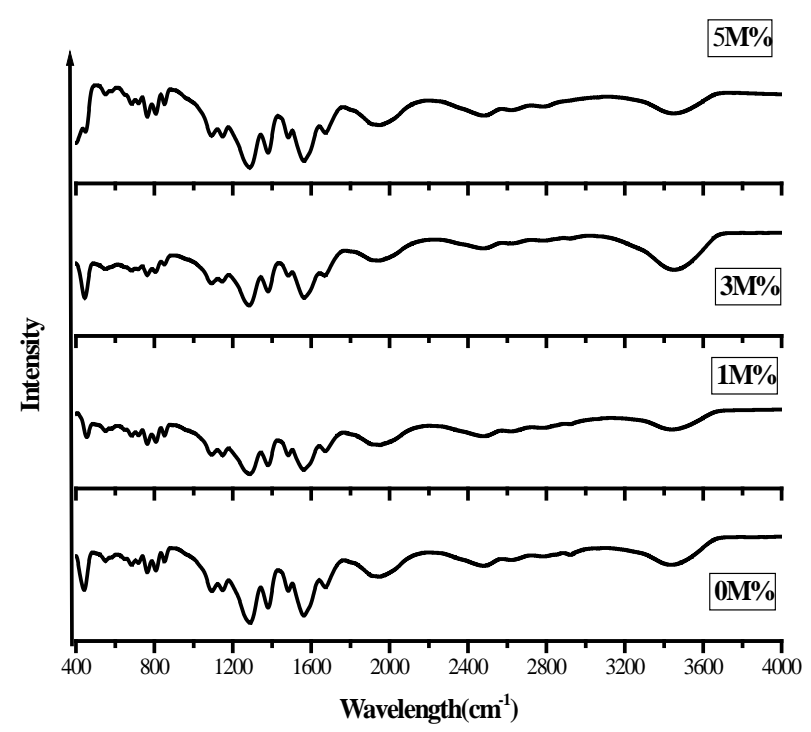

Figure 3. FTIR spectra of pure and doped crystals.

Table 1. FT-IR frequencies assignments of pure and doped crystals.

\begin{tabular}{|c|c|c|c|c|}
\hline Functional groups & $\begin{array}{l}\text { Pure KHP } \\
\mathrm{cm}^{-1}\end{array}$ & $\begin{array}{c}\mathrm{KHP}+1 \mathrm{M} \% \\
\mathrm{~cm}^{-1}\end{array}$ & $\begin{array}{c}\mathrm{KHP}+3 \mathrm{M} \% \\
\mathrm{~cm}^{-1}\end{array}$ & $\begin{array}{c}\mathrm{KHP}+5 \mathrm{M} \% \\
\mathrm{~cm}^{-1}\end{array}$ \\
\hline $\mathrm{C}=\mathrm{O}$ symmetrical stretching & 1566 & 1566 & 1565 & 1560 \\
\hline $\mathrm{O}=\mathrm{C}$ stretching & 1482 & 1484 & 1484 & 1484 \\
\hline $\mathrm{C}-\mathrm{C}=\mathrm{O}$ stretching & 1085 & 1085 & 1085 & 1092 \\
\hline C-H plane bend & 870 & 859 & 859 & 854 \\
\hline O-H stretching & 3441 & 3441 & 3443 & 3452 \\
\hline $\mathrm{C}=\mathrm{C}$ asymmetric stretching & 1945 & 1942 & 1940 & 1955 \\
\hline $\mathrm{C}=\mathrm{O}$ symmetrical stretching & 441 & 454 & 444 & 447 \\
\hline $\mathrm{C}=\mathrm{C}$ stretching & 1381 & 1382 & 1381 & 1379 \\
\hline
\end{tabular}

and doped crystals between $30^{\circ} \mathrm{C}$ to $1000^{\circ} \mathrm{C}$ in Nitrogen atmosphere with heating rate of $10^{\circ} \mathrm{C} / \mathrm{min}$. From the TG curve, it is evident that the pure $\mathrm{KHP}$ is stable up to $303^{\circ} \mathrm{C}$ [22] [23]. In doped crystals are $308^{\circ} \mathrm{C}, 308^{\circ} \mathrm{C} \&$ $309^{\circ} \mathrm{C}$ respectively for $1 \mathrm{M} \%$, $3 \mathrm{M} \%$ \& $5 \mathrm{M} \%$, no decomposition. This shows that, there is a slight increase in melting point due to effect of doping ensures the stability. The TG-DTA curves for doped and undoped samples shows two stage weight loss patterns. The first major weight loss occurred between the temperatures $269^{\circ} \mathrm{C}$ and $303^{\circ} \mathrm{C}$ with $40 \%$, this weight loss. The second stage weight loss noticed between the temperatures $303^{\circ} \mathrm{C}$ and $494^{\circ} \mathrm{C}$ experiences a weight loss of about $60 \%$ with complete decomposition of Phthalic acid. The TG curves shows that pure and doped KHP crystals are stable upto $303^{\circ} \mathrm{C}$ and can be designed for device application in this temperature range.

\subsection{UV-Visible Spectral Studies}

The grown crystals of pure and urea doped KHP were subjected to optical absorption studies. The samples scanned in the wavelength range $200-900 \mathrm{~nm}$. The high percentage of transmission in the entire visible region is observed for all samples and an important property for NLO applications. It is observed that, no significant change in the cut-off wavelength for doped crystals. The UV-Vis spectra are shown in Figure 5 which shows these crystals can be used for optical device fabrication. 


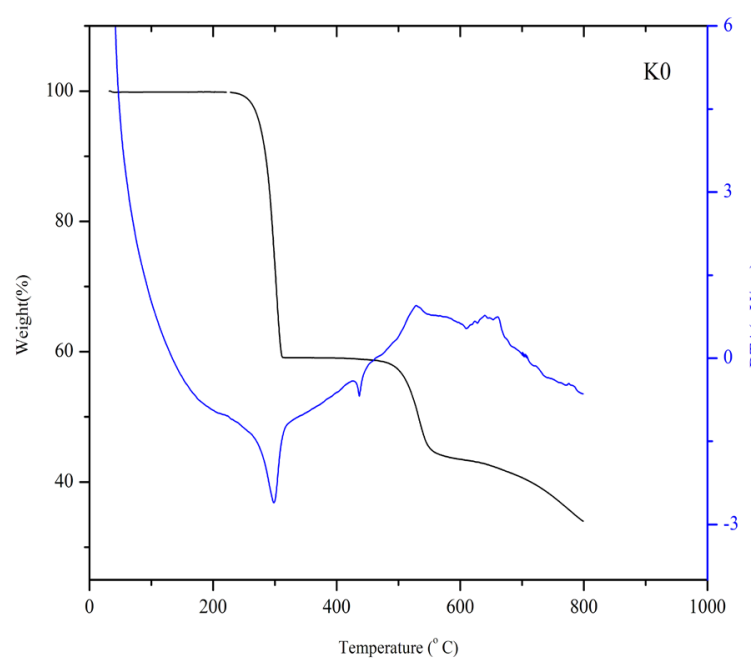

(a)

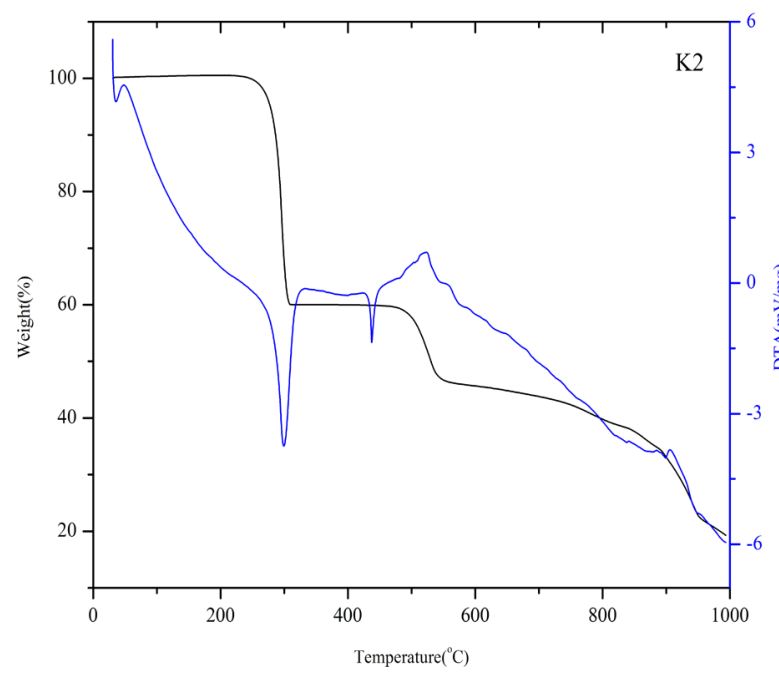

(c)

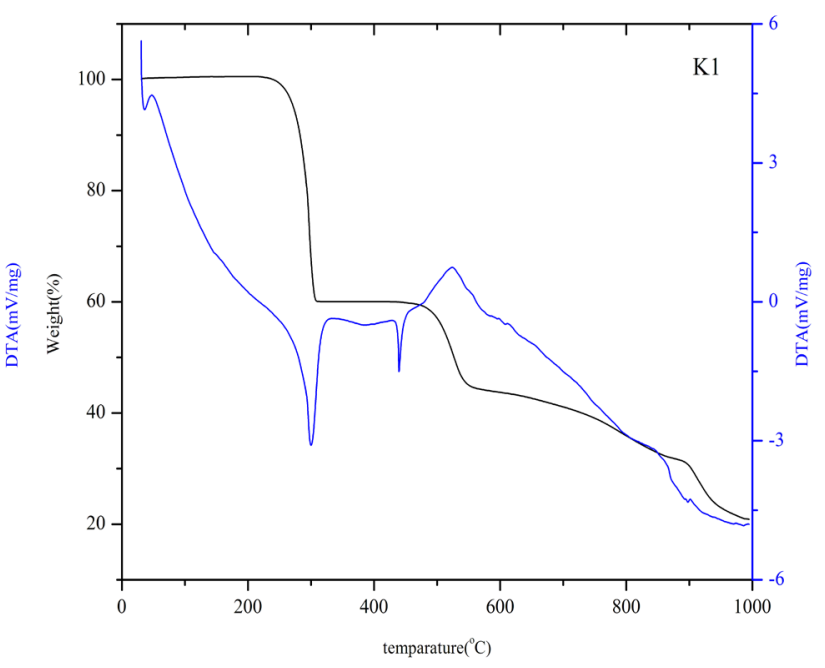

(b)

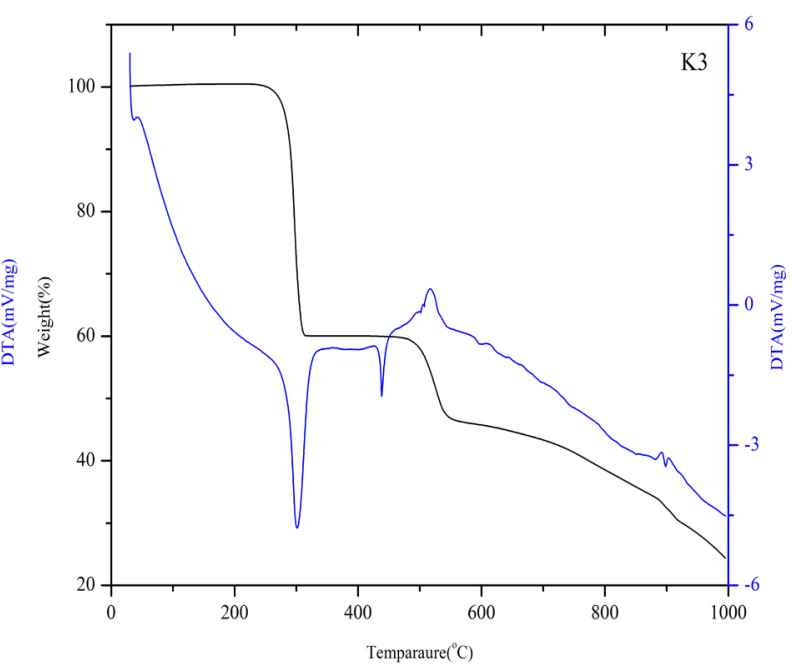

(d)

Figure 4. (a) TG-DTA of K0; (b) TG-DTA of K1; (c) TG-DTA of K2; (d) TG-DTA of K3.

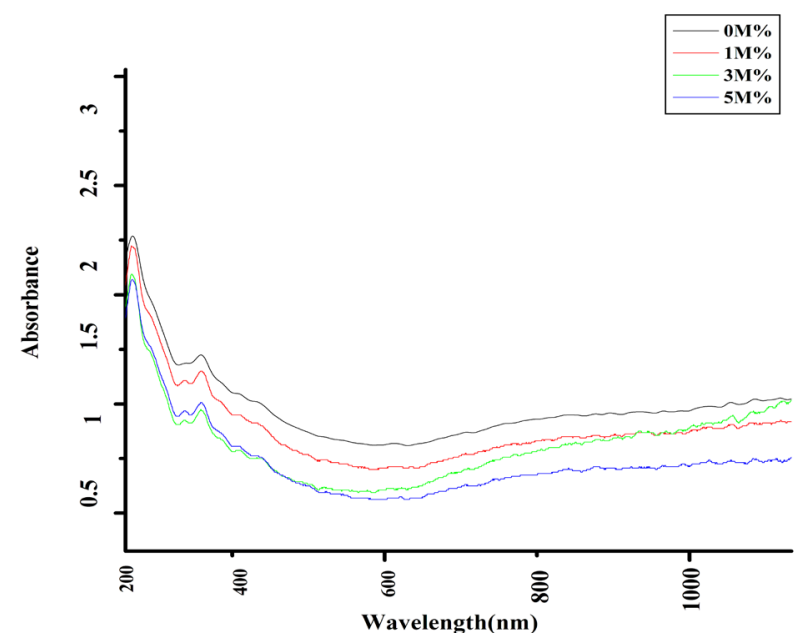

Figure 5. UV-visible spectra. 


\subsection{Photoluminescence Studies}

The PL spectrum of pure and doped crystals when excited with laser of wavelength 325 nm are shown in Figure 6. Broad peaks from green to violet emissions for pure and doped KHP crystals observed. There is no significant change in peak but shift from $416 \mathrm{~nm}$ to $406 \mathrm{~nm}$ is observed with increase in dopent concentration, which shows the enhancement fluorescence which act as ligand. The intermolecular energy transfer is also facilitated which may enhance fluorescence [24] [25]. A peak at $493 \mathrm{~nm}$ and $498 \mathrm{~nm}$ corresponds to 3M\% \& 5M\% doping of alkali metal.

\subsection{NLO Studies}

Second harmonic generation (SHG) test was performed on these crystals by Kurtz powder technique [26] with input radiation of $5.0 \mathrm{~mJ} /$ pulse. The Nd:YAG laser of $1064 \mathrm{~nm}$ radiation was used as optical source and directed on powder sample filled in microcapillary tubes. The frequency doubling was confirmed with green radiation emission. The output SHG intensities for pure and doped samples give relative NLO efficiencies of the measured samples are tabulated below (Table 2) with Urea as reference sample. It is observed that enhancement of SHG efficiency with dopant and found that SGH efficiency is concentration dependent. Many materials have been identified with higher molecular non-linearity, the attainment of SHG effects requires favorable alignments of the molecule within the crystal structure which can be achieved facilitating nonlinearity in the presence of solvent [27]. The SGH can be enhanced by attaining the molecular alignment through inclusion complexation [28]. It is reported that enhancement in crystalline perfection could lead to the increase in NLO efficiency [29].

\subsection{Dielectric Studies}

The Dielectric measurements were done on pure and $\mathrm{NaCl}$ doped KHP crystals using Impendence analysis Interface LCR meter Model PSM 1735 N4L. Dielectric permittivity measurements were carried out for silver pasted pure and doped samples for electrical contact at room temperature for different frequencies. The dielectric constant have been calculated using the equation $\epsilon_{\mathrm{r}}=\mathbf{C d} / \mathbf{A} \epsilon_{\mathbf{0}}$ where $\mathrm{d}$ is the thickness of the sample, A is the area of the sample. Measurements are made in the frequency in the range $1000 \mathrm{~Hz}$ to $35 \mathrm{MHz}$. The variations of dielectric constant with frequency for pure and doped samples are shown in the Figure 7. It is observed that, at low frequencies values of $\boldsymbol{\epsilon}_{\mathbf{r}}$ were maximum and decreased with increasing frequency and attains saturation at higher frequencies. The high value of dielectric constant of the crystal at low frequency is due to space charge polarization [30] [31]. According to the Miller rule, the lower value of dielectric constant at higher

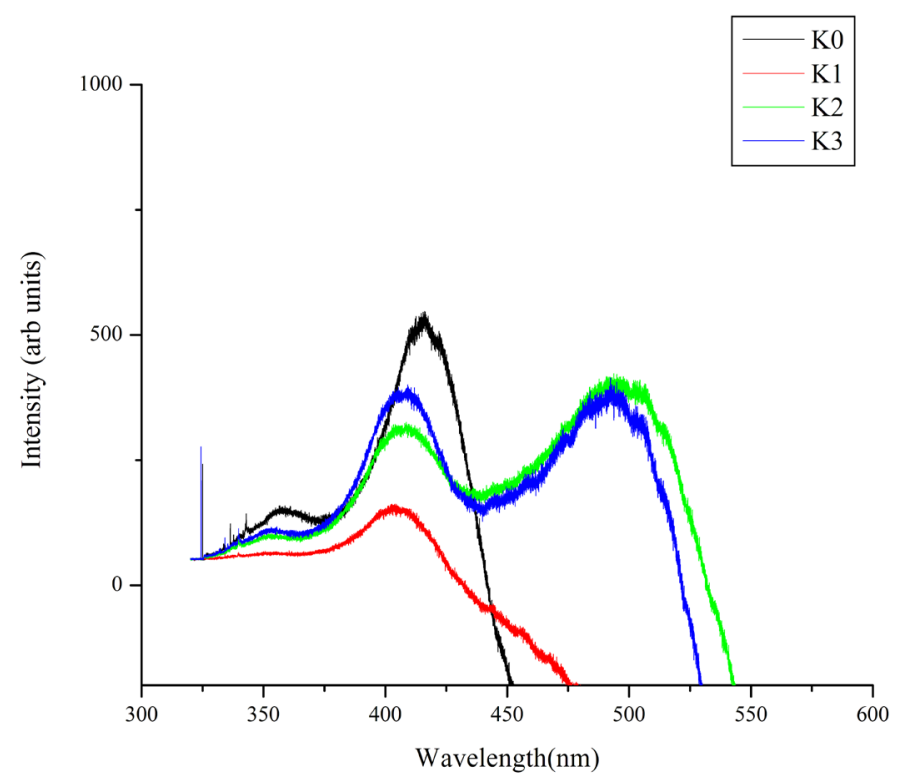

Figure 6. Photoluminiscience spectra. 
Table 2. The SGH output.

\begin{tabular}{cc}
\hline Sample & SGH output $\mathbf{I}_{\mathbf{2}} /(\mathbf{m V})$ \\
\hline Urea (ref) & 320 \\
Pure KHP & 92 \\
KHP + 1M\% & 110 \\
KHP + 3M\% & 94 \\
\hline
\end{tabular}

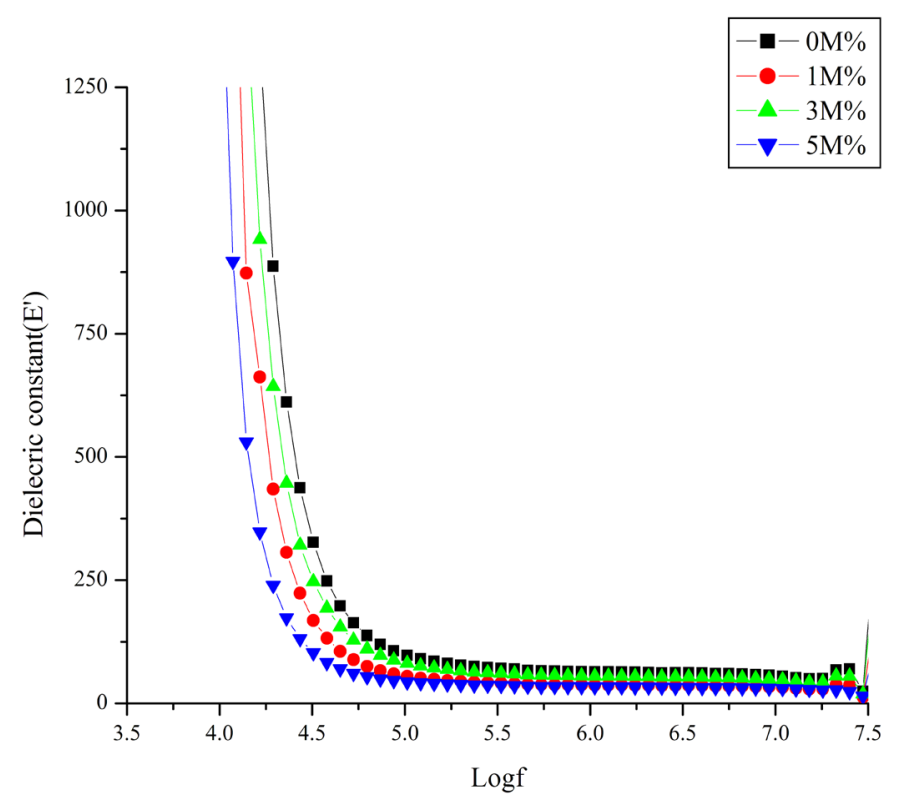

Figure 7. Dielectric studies.

frequencies is a suitable parameter for enhancement of SHG coefficient [32]. The variation of dielectric constant is due to the incorporation of dopant inside the KHP crystal lattice and also lower value for higher concentration of dopant with frequency suggests that the crystal possess enhanced optical quality with lesser defects and this property plays important role for the optoelectronic devices [33].

\section{Conclusion}

Single crystals of pure and $\mathrm{NaCl}$ doped Potassium hydrogen phthalate (KHP) have been grown by slow evaporation technique at room temperature. The powder X-ray diffraction studies confirmed the incorporation of sodium ions into the crystal lattice of KHP and also calculated lattice parameters. The FT-IR spectral analysis confirms presence of functional groups of KHP. TG-DTA analysis showed that the crystals were stable upto melting point without any decomposition. The UV-visible spectra show that pure \& doped crystals have good optical transmittance in the entire visible region which is desirable property for opto-electronics. The powder SHG test confirms the NLO property of pure and doped KHP crystals. The dielectric studies of all samples show that dielectric constant decreases slowly with increasing frequency and attains saturation at higher frequencies.

\section{References}

[1] Marcy, H.O., Warren, L.F., Webb, M.S., Ebbers, C.A., Velsko, S.P., Kennedy, G.C. and Catella, G.C. (1992) SecondHarmonic Generation in Zinc Tris(Thiourea) Sulfate. Applied Optics, 31, 5051-5060. http://dx.doi.org/10.1364/AO.31.005051

[2] Jones, L., Paschen, K.W. and Nicholson, J.B. (1963) Performance of Curved Crystals in the Range 3 to 12A. Applied Optics, 2, 955-961. 
[3] Miyashita, Y.O., Murakami, A., Aoki, K. and Yamaguchi, S. (1991) Proceedings of the SPIE-The International Society for Optical Engineering, 1503, 463.

[4] Sudhahar, S., Krishnakumar, M., Jayaramakrsishanan, V., Muralidharan, R. and Mohankumar, R. (2014) Effect of $\mathrm{Sm}+$ Rare Earth Ion on the Structural, Thermal, Mechanical and Optical properties of Potassium Hydrogen Phthalate Single Crystals. Journal of Materials Science and Technology, 30, 13-18. http://dx.doi.org/10.1016/j.jmst.2013.08.017

[5] George, J. and Premachanran, S.K. (1981) Dislocation and Indentation Studies on Potassium Acid Phthalate Crystals. Journal of Physics D: Applied Physics, 14, 1277-1281. http://dx.doi.org/10.1088/0022-3727/14/7/015

[6] Khant, M.D.S. and Narasimhamurthy, T.S. (1982) Elasto-Optic Studies on Potassium Acid Phthalate Single Crystal. Journal of Materials Science Letters, 1, 268-270.

[7] Comoretto, D., Rossi, L. and Borghesi, A. (1997) Optical Properties of Potassium Acid Phthalate. Journal of Materials Science Letters, 12, 1262-1267.

[8] Bhat, S.G. and Dharmaprakash, S.M. (1998) A New Metal-Organic Crystal: Bismuth Thiourea Chloride. Materials Research Bulletin, 33, 833. http://dx.doi.org/10.1016/S0025-5408(98)00049-X

[9] Meenakshisundaram, S., Parthiban, S., Sarathi, N., Kalavathy, R. and Bhagavannarayana, G. (2006) Effect of Organic Dopants on ZTS Single Crystals. Journal of Crystal Growth, 293, 376-381. http://dx.doi.org/10.1016/j.jcrysgro.2006.04.094

[10] Belyaev, L.M., Belikova, G.S., Gil’varg, A.B., et al. (1969) Soviet Physics-Crystallography, 14, 544-549.

[11] Belikova, G.S., Belyaev, L.M., Goloveï, M.P., et al. (1974) Soviet Physics Crystallography, 19, 351-355.

[12] Okaya, Y. (1965) The Crystal Structure of Potassium Acid Phthalate, $\mathrm{KC}_{6} \mathrm{H}_{4} \mathrm{COOH} . \mathrm{COO}$. Acta Crystallographica, 19, 879-882. http://dx.doi.org/10.1107/S0365110X65004590

[13] Enculescu, M. (2010) Morphological and Optical Properties of Doped Potassium Hydrogen Phthalate Crystals. Physica B: Condensed Matter, 405, 3722-3727. http://dx.doi.org/10.1016/j.physb.2010.05.074

[14] Timpanaro, S., Sassella, A., Borghesi, A.Z., Porzio, W., Fontaine, P. and Goldmann, M. (2001) Crystal Structure of Epitaxial Quaterthiophene Thin Films Grown on Potassium Acid Phthalate. Advanced Materials, 3, 127-130. http://dx.doi.org/10.1002/1521-4095(200101)13:2<127::AID-ADMA127>3.0.CO;2-Y

[15] Stemmler, B.L. and Legrand, P. (1995) Measurement of the X-Ray Spectrometric Properties of Cesium Hydro Phthalate (CsAP) Crystal with the Synchrotron Radiation. Review of Scientific Instruments, 66, 1601. http://dx.doi.org/10.1063/1.1145920

[16] Benedict, J.B., Wallace, P.M., Reid, P.J. and Jang, S.-H. (2003) Up-Conversion Luminescence in Dye-Doped Crystals of Potassium Hydrogen Phthalate. Advanced Materials, 15, 1068-1070. http://dx.doi.org/10.1002/adma.200303715

[17] Prasad, P.N. and Williams, D.J. (1991) Introduction to Nonlinear Effects in Molecules and Polymers. Wiley, Berlin.

[18] Zhang, H.W., Batra, A.K. and Lal, R.B. (1994) Growth of Large Methyl-(2,4-Dinitrophenyl)-Aminopropanoate: 2-Methyl-4-Nitroaniline Crystals for Nonlinear Optical Applications. Journal of Crystal Growth, 137, 141-144. http://dx.doi.org/10.1016/0022-0248(94)91262-9

[19] Kuznetsov, V.A., Okhrimenko, J.M. and Rak, M. (1998) Growth Promoting Effect of Organic Impurities on Growth Kinetics of KAP and KDP Crystals. Journal of Crystal Growth, 193, 164-173. http://dx.doi.org/10.1016/S0022-0248(98)00489-8

[20] Ramsamy, G., Parthiban, S., Meenakshisundaram, S.P. and Mojumdar, S.C. (2010) Influence of Alkali Metal Sodium Doping on the Properties of Potassium Hydrogen Phthalate (KHP) Crystals. Journal of Thermal Analysis and Calorimetry, 100, 861-865. http://dx.doi.org/10.1007/s10973-010-0678-z

[21] Shannon, R.D. (1976) Revised Effective Ionic Radii and Systematic Studies of Interatomic Distances in Halides and Chalcogenides. Acta Crystallographica Section A, A32, 751-767. http://dx.doi.org/10.1107/S0567739476001551

[22] Vasudevan, G., Anbusrinivasan, P., Madhurambal, G. and Mojumdar, S.C. (2009) Thermal Analysis, Effect of Dopants, Spectral Characterisation and Growth Aspects of KAP Crystals. Journal of Thermal Analysis and Calorimetry, 96, 99102. http://dx.doi.org/10.1007/s10973-008-9880-7

[23] Meenakshisundaram, S.P., Parthiban, S., Madhurambal, G. and Mojumdar, S.C. (2008) Effect of Chelating Agent (1,10-Phenanthroline) on Potassium Hydrogen Phthalate Crystals. Journal of Thermal Analysis and Calorimetry, 94, 21-25. http://dx.doi.org/10.1007/s10973-008-9182-0

[24] Muthu, K., Bhagavannarayana, G., Chandrasekaran, C., Parthiban, S., Meenakshisundaram, S.P., and Mojumdar, S.C. (2010) Os(VIII) Doping Effects on the Properties and Crystalline Perfection of Potassium Hydrogen Phthalate (KHP) Crystals. Journal of Thermal Analysis and Calorimetry, 100, 793-799. http://dx.doi.org/10.1007/s10973-010-0759-z

[25] Gayathri, K., Krishnan, P., Rajkumar, P.R. and Anbalagan, G. (2014) Growth, Optical, Thermal and Mechanical Characterization of an Organic Crystal: Brucinium 5-Sulfosalicylate Trihydrate. Bulletin of Materials Science, 37, 15891595. http://dx.doi.org/10.1007/s12034-014-0721-y 
[26] Kurtz, S.K. and Perry, J.J. (1968) A Powder Technique for the Evaluation of Nonlinear Optical Materials. Journal of Applied Physics, 39, 3798. http://dx.doi.org/10.1063/1.1656857

[27] Meenakshisundaram, S., Parthiban, S., Bhagavannarayana, G., Madhurambal, G. and Mojumdar, S.C. (2006) Influence of Organic Solvent on Tristhioureazinc(II)Sulphate Crystals. Journal of Thermal Analysis and Calorimetry, 96, 125129. http://dx.doi.org/10.1007/s10973-008-9884-3

[28] Rak, M., Eremin, N.N., Eremina, T.A., Kuznetsov, V.A., Okhrimenko, T.M. and Furmanova, N.G. (2005) On the Mechanism of Impurity Influence on Growth Kinetics and Surface Morphology of KDP Crystals-I: Defect Centres Formed by Bivalent and Trivalent Impurity Ions Incorporated in KDP Structure-Theoretical Study. Journal of Crystal Growth, 273, 577-585. http://dx.doi.org/10.1016/j.jcrysgro.2004.09.067

[29] Wang, Y. and Eaton, D.F. (1985) Optically Non-Linear Organic Molecules Cyclodextrin Inclusion Complexes. Chemical Physics Letters, 120, 441-444. http://dx.doi.org/10.1016/0009-2614(85)85637-2

[30] Narasimha, B., Choudhary, R.N. and Roa, K.V. (1988) Dielectric Properties of $\mathrm{LaPO}_{4}$ Ceramics. Journal of Materials Science, 23, 1416-1418. http://dx.doi.org/10.1007/BF01154610

[31] Roa, K.V. and Samakula, C. (1965) Dielectric Properties of Cobalt Oxide, Nickel Oxide, and Their Mixed Crystals. Journal of Applied Physics, 36, 2031. http://dx.doi.org/10.1063/1.1714397

[32] von Hundelshausen, U. (1971) Electrooptic Effect and Dielectric Properties of Cadmium-Mercury-Thiocyanate Crystals. Physics Letters A, 34, 405-406. http://dx.doi.org/10.1016/0375-9601(71)90939-x

[33] Balarew, C. and Duhlew, R. (1984) Application of the Hard and Soft Acids and Bases Concept to Explain Ligand Coordination in Double Salt Structures. Journal of Solid State Chemistry, 55, 1-6.

http://dx.doi.org/10.1016/0022-4596(84)90240-8 